\title{
CARTOGRAPHY AND MAPPING FOR PRECISION HEALTH: REVIEW OF ESSENTIAL ELEMENTS FOR DISEASE MAPPING
}

\author{
Muhammad Naim Ramli ${ }^{1}$, Abdul Rauf Abdul Rasam ${ }^{1,2 *}$ and Mohd Adly Rosly ${ }^{1}$ \\ ${ }^{1}$ Centre of Studies for Surveying Science and Geomatics, Faculty of Architecture, Planning and Surveying, \\ ${ }^{2}$ Environmental and Social Health Research Group, Health and Wellbeing Research Community, \\ Universiti Teknologi MARA, Shah Alam, Selangor. \\ muhammadnaimramli158@gmail.com,rauf@uitm.edu.my*,mohdadly@uitm.edu.my
}

Commission 4, WG 7

KEY WORDS: Cartography, Geospatial Mapping, Precision Health, Disease Mapping

\begin{abstract}
A well-developed healthcare system, decent access to clean water and sanitation, and programmes to eliminate poverty and build modern infrastructure are essential components to create healthier Malaysia's population. Non-communicable diseases currently account for most of the mortality and morbidity, although communicable diseases such as dengue fever, avian flu and covid-19 still pose a threat. The World Health Organization (WHO) identified COVID-19 is a rare pneumonia disease that originated in Wuhan, on January 12, 2020, before it became an outbreak in all countries including Malaysia. The requirement of a precise mapping and Cartography for the accurate disease mapping and data management are crucial due to a precise map gives higher resolution of the data and for more specific data analysis, interpretation and decision making process. In Malaysia, there no specific report on precise mapping for health applications, and it is therefore this paper is to identify the potential criteria and factors needed for precise health mapping applications. A precise health mapping is essential to create a precise risk map towards the surveillance and signal detection, predicting future risk, targeted interventions, and understanding disease phenomena.
\end{abstract}

\section{INTRODUCTION}

Tuberculosis (TB) is the leading infectious killer in the world. Every day, over 4000 people die and 30000 individuals contract tuberculosis. Tuberculosis is contagious and spreads through the air. Bacteria (Mycobacterium tuberculosis) cause it, and it usually affects the lungs. Tuberculosis (TB) is transmitted from person to person through the air. People with lung TB spread TB germs into the air when they cough, sneeze, or spit. To become infected, a person only needs to breath a few of these germs. About a quarter of the world's population has latent tuberculosis, which means they have been infected with the germs, but are not sick yet and cannot spread it. People who are infected with tuberculosis bacteria have a 5-10 percent lifetime risk of contracting the disease.

People with weakened immune systems, such as those with HIV, malnutrition, or diabetes, or those who smoke, are at a considerably higher risk of being ill. Nowadays, precise health mapping is the one of the important because that can estimate, prediction and solve the risk of health in the public society. That can estimate risk of an individual or possibly such as socioeconomic or level of pollution. That's why I will be reviewed about precise, precise mapping, mapping disease and precise mapping disease or health. Therefore, it includes what the term for each and how to define the term of each. It also will show the result for every term of each, such as precise mapping, mapping disease and precise mapping disease while the importance of the mapping disease also can be explained.

Then, with this review that can conclude what is the importance of the health mapping and with more precise that can get to the future of health and for the world. After that, it also can give the knowledge about precise health mapping and what method that need to used or show to get the good of data collection and to make the map more precision and more accurate which is the disease risk factor, damage and so on while it can solve the risk of health in the public society and predict the future of risk for the country or region to achieve their goals for every sites information gathered on the field. The planning, construction of new utilities and excavation of existing utilities requires detailed information about the current underground utilities

\section{LITERATURE REVIEW}

This section discussed the definition and principles of material. Besides, the characterize of precise health mapping application are elaborated.

\subsection{Term of Precision}

Precision is the quality of the methods or measurements to get the truth value which that meant most probability value (MPV) with analysis the random errors in term traditional definitions. For the example, the true value that has estimate is $12 \mathrm{~m}$ and it will be measured randomly or repeat measures with first data, second data to the 10 data that are collected. So, it will be calculated the random errors of the 10 data to get which one is the true value. That meant precision is to estimates the spread of the data which is the high precision is with value are close each other's when the value that randomly measured to the reference of the true value of these data. That's why when can more data or random data, the value of the data to get the true value or data will be more precision or high precision. Soon, the true of data and value can be the data or value that can estimate, risk, predict or solve the problem with the truthfulness of the data or value. (Selvik \& Abrahamsen, 2017).

Precision public health is an emerging practice to more granularly predict and understand public health risks and customize treatments for more specific and homogeneous subpopulations, often using new data, technologies, and 
methods. Big data is one element that has consistently helped to achieve these goals, through its ability to deliver to practitioners a volume and variety of structured or unstructured data not previously possible. Big data has enabled more widespread and specific research and trials of stratifying and segmenting populations at risk for a variety of health problems. Examples of success using big data are surveyed in surveillance and signal detection, predicting future risk, targeted interventions, and understanding disease. Big data success will likely be a required pillar of precision public health in the future. (Dolley, 2018)

\subsection{Precise Mapping}

Precision mapping gives higher resolution of the data which more information, more specific or that meant the data will be more interpret and more detailed about the data while in the small space. That's why the map will be increased with higher resolution, spatial resolution, which the data that need to collect must be in the targeted zones, available resources and allows for the better data. So that to get the precise mapping, the innovative tool and promising tool need to shrink the map or data or resources of the map. (Tchuem et al., 2018)

By using the extra sensor, extra data, extra method of the feature layers of map information, which is for the one layer of the land use, that are collected with the more of method to measure. More precise and accuracy of the map with the more extra method need to do with every single of the data or information to create the map is achieved sufficient in high resolution and more elements in the map. (Tchuem Tchuenté et al., 2018)

Low-altitude remote sensing unmanned aerial vehicle (UAV) technology has been widely accepted in various industries for its high precision in mapping, and it has become a critical spatial data collecting technology. The use of UAV low-altitude remote sensing photographs in real estate registration is a new trend. Traditional manual land area measurements, both developed and undeveloped, take a long time, effort, and money. Traditional aerial Photogrammetry techniques are very time-consuming, and flying costs are significant. UAV remote sensing has numerous advantages over traditional human measurements and aerial Photogrammetry for small research areas. Low flying, heights, high precision, and large-scale measurements, save labour and material expenses, making it flexible, low-cost, safe, reproducible, and dependable. (Liu et al., 2018)

The precision map that has comparison with conventional maps of health districts between Districts A and Districts B at Cameroon which is the map A1 and $\mathrm{B} 1$ more precision with more accurate information on the distribution of health or disease within districts and a very clear precision on the subdistricts between conventional map, which is A2, B2, A3, and $\mathrm{B} 3$ as shown in the Figure 1.

That means map A1 and B1 give more precise and accurate information which is about socio economic, cultural and health care at their District. The information is poor living conditions, public health services, large population, distance to healthcare, socio-economic level which is risk group or low income and type of property in the Figure 1

That why, map A1 and B1 more precision with more accurate information on the distribution of health or disease and a very clear precision information on the district which is called precision map or the precise mapping in the Figure 1.
At the easy word to understand, "In a one map or mapping, that will give more of data and information more than one". That shown in the Figure 1.

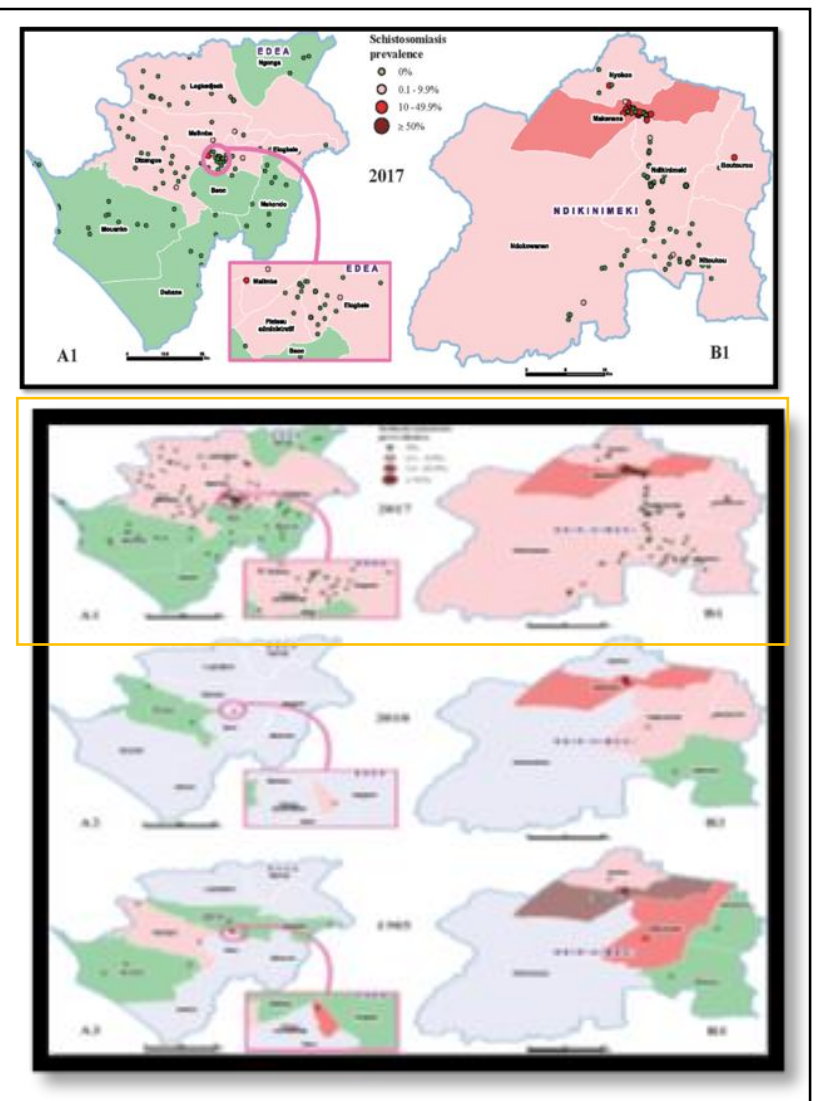

Figure 1. Comparison of precision and conventional maps in the health districts of (Districts A) and (Districts B), Cameroon. (Tchuem Tchuenté et al., 2018)

\subsection{Mapping Disease, Medicine and Health}

The mapping of disease prevalence and occurrence has been going on for a long time a part of public health which is the study of disease in human residents or populations about the society or the environment. The small administrative districts or regions must be a relationship with potential allowable background information such as the risk of individuals number, socioeconomic status measures, levels of pollution or environmental levels and the age distribution. (Bigger \& Catelan, 2012)

The mapping disease or health is the study of data analysis and visualization and public health professionals for the monitoring, planning, predict and surveillance will be increasing use it. By presenting data that are analytic in maps, it can give more insight than a table of the same data or the data on the paper only. It also can provide quick assessments of interrelationships and trends. So, public health initiatives or prediction will be assisting targeted as well as the capability of map disease or health which is informing long term planning and evaluating or calculate health programs. Transport infrastructure and health resources are often poor with challenge in developing countries where providing equitable minimum health services is a particular which is the primary determinant of utilization of these services is access to health services and mapping disease or health will be increasing used to evaluate or calculate the distribution of health resources (Fisher \& Myers, 2011) 
Disease mapping studies continue to be interested in high resolution remotely sensed (RS) data products. However, prohibitive costs had previously limited the use of satellitederived products. There is also an unprecedented space activity, with frequent satellite launches for a variety of reasons, the most important of which is a land cover observation. As a result, there is a need for knowledge on the types of data products that can be obtained from collecting satellite photos to make access and exploitation easier. With the introduction of Unmanned Aerial Vehicles/drones and spatially explicit images being obtained at relatively low costs, the remote sensing landscape is clearly shifting. RS products have been utilized in investigations of epidemiological disease mapping, such as malaria risk mapping. (Dlamini et al., 2019)

Disease mapping has long been regarded as one of the most essential public health challenges, resulting from a knowledge of the link between health and geography. For decades, scientists and academics have been trying to figure out how this link works. Dr. Snow used the disease mapping approach for the first time in 1854, when he mapped a cholera outbreak in London, England. The mapping outputs of GIS, on the other hand, are one of the most useful roles in public health. One of the most important GIS technologies is disease mapping, which has been rapidly evolving. GIS is increasingly employing this technology as an effective tool in disease surveillance. GIS can be used to map the geographical distribution of illness prevalence, trends in disease transmission, and spatially model environmental elements of disease occurrence. In Jeddah, Saudi Arabia, a GIS application was designed to produce maps and cluster modelling of three diseases: diabetes, asthma, and hypertension. The information on these disorders came from patient records at health centres. (Murad \& Khashoggi, 2020).

Disease mapping, disease clustering, and ecological analysis are the three primary categories of studies on the geographical distribution of diseases. To examine spatial relationships within the affected area, GIS-based disease mapping relies on identifying several aspects, the most essential of which is disease occurrence sites, patterns of disease transmission, environmental risk factors that lead to disease transmission, and socio-economic data. (Murad \& Khashoggi, 2020)

The study of the disease's spatial distribution is known as disease mapping. When inference regarding illness risk is necessary, it usually focuses on statistical modelling illness outcomes. With that goal, four key areas of focus might be considered which is a relative risk estimate, illness clustering, ecological analysis, and surveillance. Disease risks vary across time and space because of a variety of factors, including environmental exposures like air pollution and the prevalence of lifestyle choices like smoking. Quantifying and explaining this spatio-temporal variation in disease risk is critical for public health, as it allows risk factors to be emphasized to the public and informed decisions to be made regarding future health resource allocation. (Lawson \& Lee, 2017)

Tuberculosis (TB) is Ethiopia's greatest cause of mortality from an infectious disease, killing more than 30,000 people each year. Poor TB treatment outcomes varied across Ethiopia at the district and zone levels, and it was unclear if this variation was linked to socioeconomic, behavioural, health care access, or climatic factors. For the years 2015-2017, national TB data submitted to the health management information system (HMIS) was used to conduct a geographical analysis. The prevalence of poor TB treatment outcomes was determined by dividing the total number of $\mathrm{TB}$ patients by the sum of treatment failure, death, and loss to follow-up. Low-income countries and low-socioeconomic groups within countries have disproportionately poor TB treatment outcomes. TB control programs and health care providers need to be able to identify patterns of TB treatment result across geographic areas to plan, implement, monitor, and evaluate control and prevention initiatives in high-risk areas. (Alene et al., 2019). Figure 2 and Figure 3 shown the mapping disease about dengue and TB.

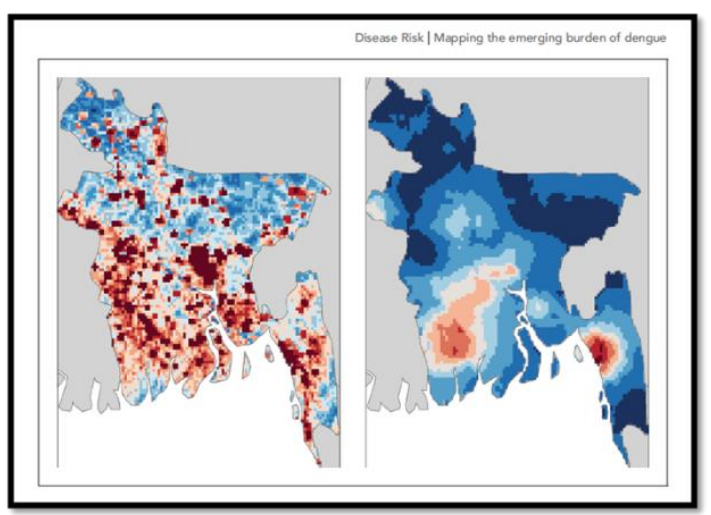

Figure 2. Mapping of Dengue (Salje et al., 2019)

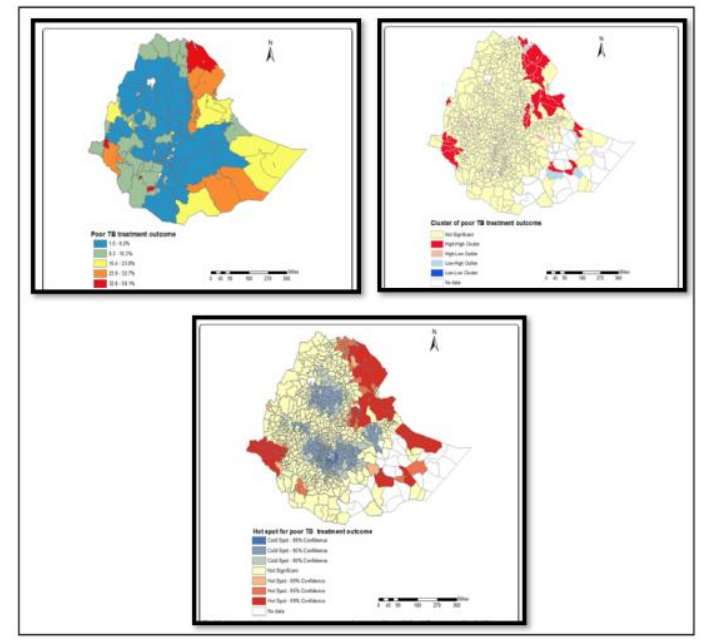

Figure 3. Mapping Disease of TB (Alene et al., 2019)

\subsection{Precise Disease}

Tuberculosis is still a major public health issue in poor communities around the world. In high-burden environments, communal gathering areas account for most of the TB transmission, thus researchers are looking into the social behaviour patterns of people who have developed tuberculosis and teenagers at risk of infection, as well as developing a simple and effective tool for locating transmission hot spots in high burden communities. We created a geospatial map using GIS locations that might be utilized to detect $\mathrm{TB}$ transmission risk sites in South Africa (Patterson et al., 2017)

The precise disease mapping that needs statistically precise such as lowering of variable data. For the example, the regions must be small area to make sure maintain geographic resolution and can be estimates the risk of disease of each region which is with small area, but the map shows more detail as well as broad trends. The map not just the only small area, but must be small 
size that meant the information on the map sample size and deeper in resulting of detailed map. Large national or state health surveys in the US, such as the National Health Interview Survey, the National Health and Nutrition Examination Survey, or the Behavioural Risk Factor Surveillance System.

For example, give design-based estimates of aggregate or average values at the national or perhaps state level. Even when they are big, however, such surveys frequently lack sufficient sample sizes at lower geographic levels to allow reliable, local, design-based estimates everywhere. Model-based approaches, on the other hand, provide a mechanism for "borrowing strength" across small areas to improve local estimates, which results in the smoothing of extreme rates based on small local sample numbers. (Biggeri \& Catelan, 2012). In the Figure 4 show the result or disease mapping of TB that can include precise mapping because of the small area data collected and more data information that have collected.

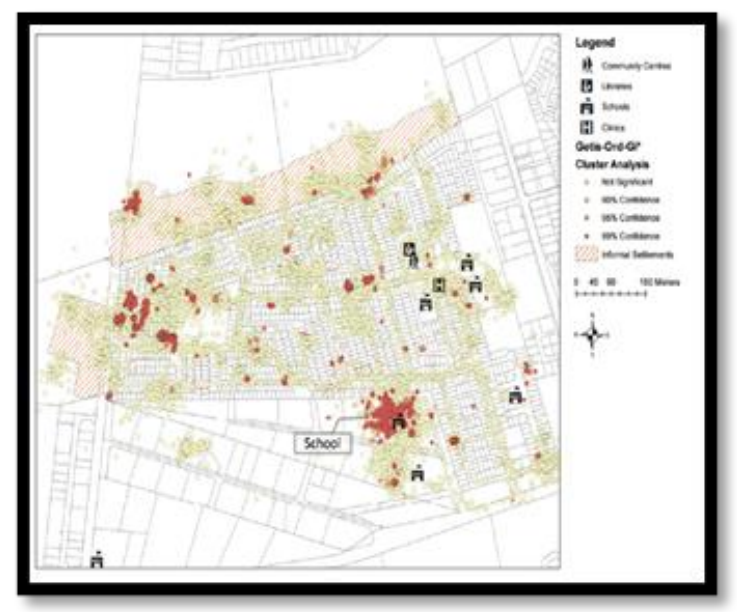

Figure 4. Hotspot Analysis of TB (Patterson et al., 2017)

\subsection{Example of Disease in Malaysia}

The most issues in Malaysia a disease of COVID-19 but for example of data that I choose is about tuberculosis (TB). In Malaysia, the Ministry of Health has a strategy called the End TB Strategy, which envisions a world free of tuberculosis, with zero fatalities, disease, or suffering because of the disease, with the objective of "ending the worldwide TB epidemic" by 2035 .

In Malaysia, tuberculosis (TB) kills between 1,500 and 2,000 people each year, with an average of six deaths each day. According to Dr Mohamed Naim Abdul Kadir, the head of the TB/Leprosy Sector of the Health Ministry's Disease Control Division, roughly 20,000 to 25,000 new TB cases are registered in Malaysia each year.

Figure 5 shown the process of big data of TB that are collected which is data socio-economic population, age, sex, healthcare, patient disease and so on from various sources with different format. For example data poverty from statistical government, health care from health government. The data will be process that call spatial database and will create new geodatabase of TB or health mapping with precise information.

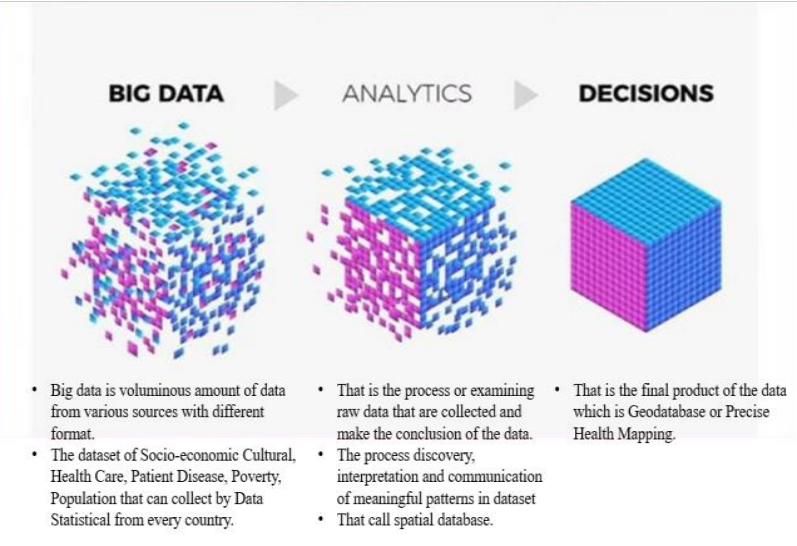

Figure 5. The process of big data collected of TB

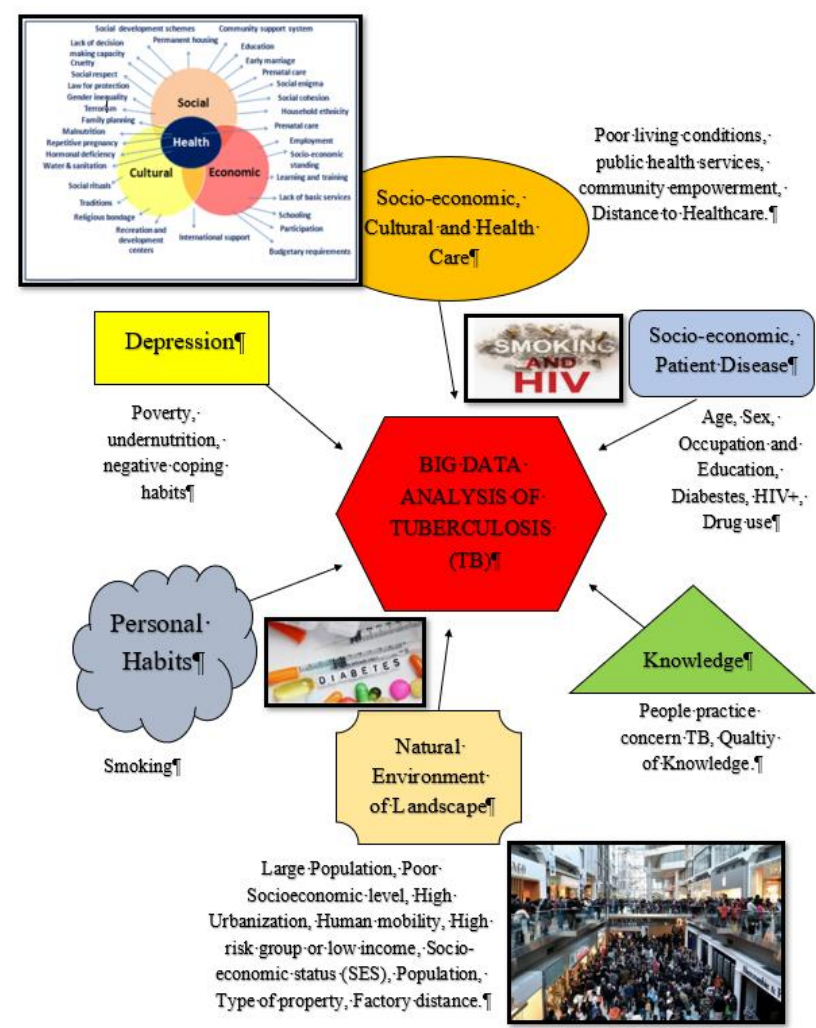

Figure 6. Big data analysis of Tuberculosis (TB)

Big data analysis of Tuberculosis (TB) that are collected. That means, data are collected in any resources with different format to make sure the geodatabase of TB or Precise Mapping of TB will be more precise and more accurate of the information that are collected in the figure 6 .

Big data analysis that can understand which is in figure 5 and figure 6 when that analyse can be performed from outbreak of data. There are containing outputs and different data in different colour with more information and the action or process needed to did. These example in figure 7 which example of outbreak data. 


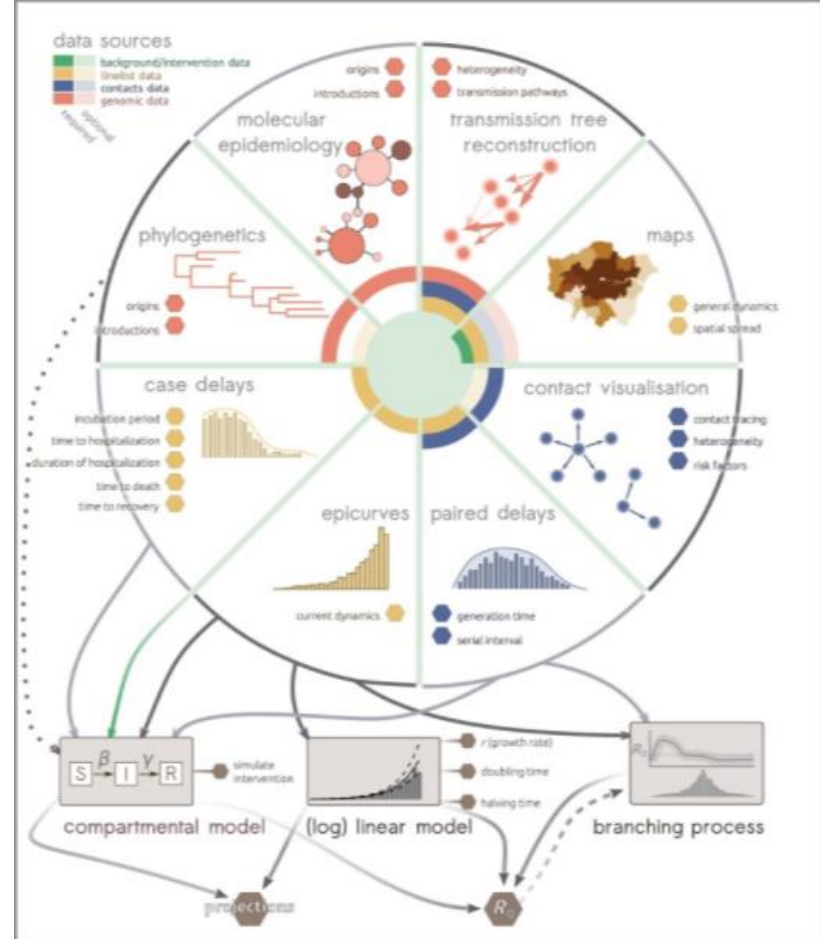

Figure 7. Outbreak data analysis (Polonsky JA et al., 2019)

Knowledge of outbreak data analysis based on all accessible data sources. It also includes the gathering, display, and analysis of source data, as well as the types of information that can be delivered to inform real-time activities. (Polonsky JA et al., 2019)

\section{METHODOLOGY}

The main methodology applied in this study is divided into three stages (Figure 8). The first stage is to study disease and mapping of disease. The second stage focus on source data and source journal. The third stage focuses on summarize and conclude this review.

3.1 Stages 1: Study Disease and Mapping: This is focussed study of disease and mapping which is the term, meaning and so on. It also evaluates what is the precise, mapping, disease mapping and precise mapping health or disease.

3.2 Stages 2: Source Data and Source Journals: In this will find the source of data by interview and read the journals which the mapping, factor or disease.

3.3 Stages 3: Summarize and Conclude: At this will be summary and conclude the review of the journal which what is the important of precise mapping health or disease and the future that can goals or create
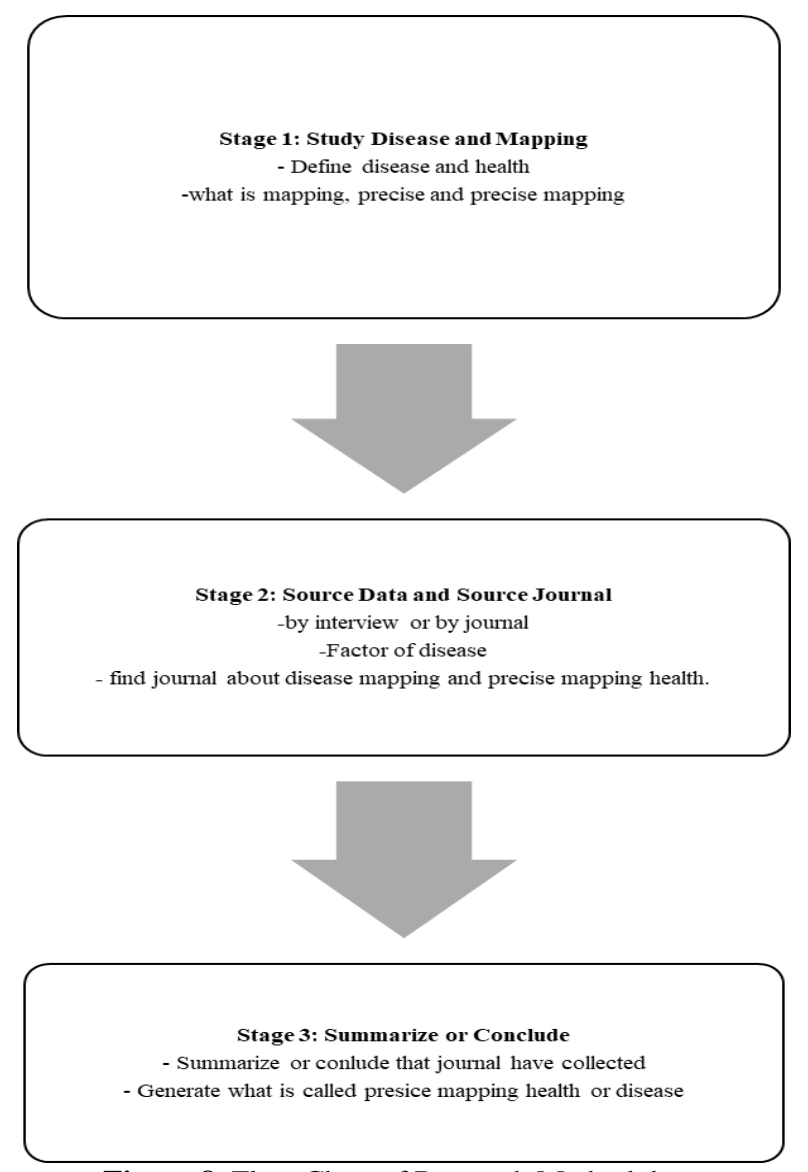

Figure 8. Flow Chart of Research Methodology

\subsection{CRITERIA AND ELEMENTS FOR PRECISE DISEASE MAPPING}

This review of the characteristics of health mapping that I can summarize which is what the precise, precise mapping, mapping disease and precise mapping disease. Precise is when the data that measured redundant such as in the smaller area or place, the data will be collected more and more that meant we has 10 data with to get one by one data need to collect more method to get the precise and accuracy of the data for the only one data. So, same step for the next data which is 2 to 10 . So that, precise mapping and mapping disease can be related to make precise disease mapping with the good or precious data information. Precise disease mapping can solve the every problem of health such costs, socioeconomic, prediction about individual health and so on.

From review in this paper, all country need disease mapping, but only United State and United Kingdom that provide precise mapping health. But, United State just makes precise mapping of the Nutrition Mapping with collected the average of the nutrition and United Kingdom just not make more data to create the hotspot analysis of TB while every single world talk about the disease, how to prevent, to predict future of risk and so on. That's why, precise mapping health or disease, every important for a country or region. 


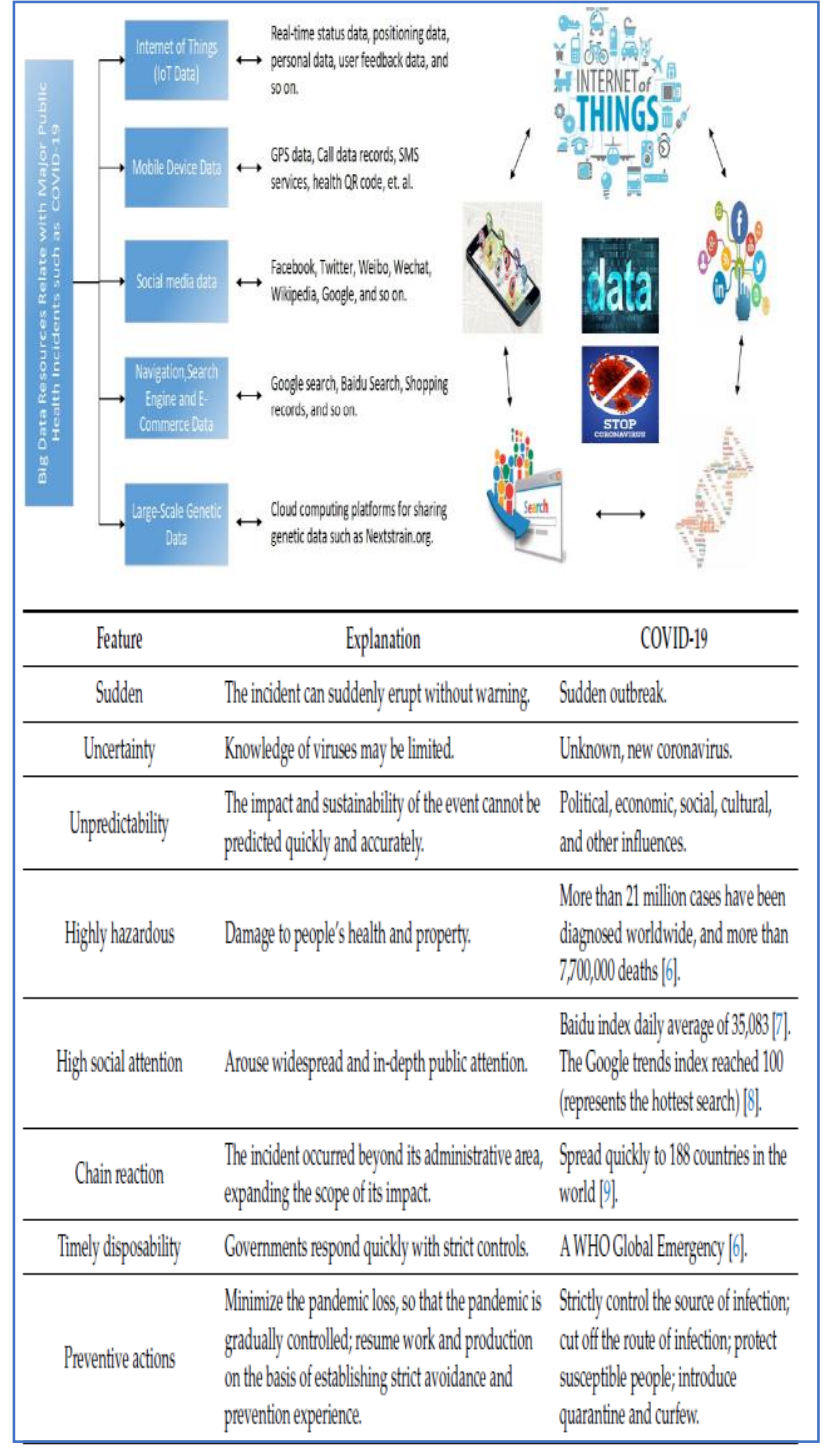

Figure 9. Big Data Analysis (IoT) and Characteristics of the Diesease (Q. Jia et al., 2020)

Figure 9 shows a big data platform that can store large amounts of data in a distributed file system, execute big data batch calculations on historical data, and deploy big data stream processing calculations on real-time data. On the processed data, we can perform data analysis, data mining, and machine learning. These new data storage and processing tools help people evaluate large amounts of data and make important management decisions. The following big data sources that can be used to help and carry out pandemic prevention and control have been summarised. Internet of Things (IoT) can be utilised for intelligent identification, placement, tracking, monitoring, and management of goods through exchanging information and communicating. In real-time, sensors can send a significant volume of static and dynamic data. These data include real-time status information, location information, personal information, and user feedback information. (Q. Jia et al., 2020)

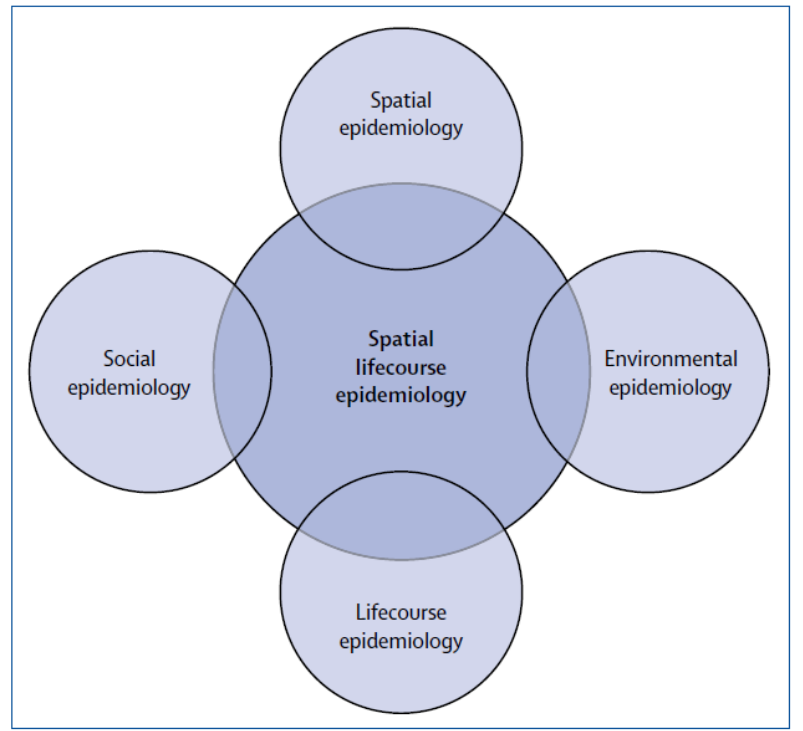

Figure 10. Conceptual framework of spatial lifecourse epidemiology (P. Jia, 2019)

In figure 10, spatial lifecourse epidemiology is the process that exposures more accurate of the epidemiology which is studies in the large areas needed. It also the advanced spatial data and location based technologies which is smartphone apps, sensors, earth observation and Internet of Things that over or more data need to be processing with the high temporal-resolution. (P. Jia, 2019)

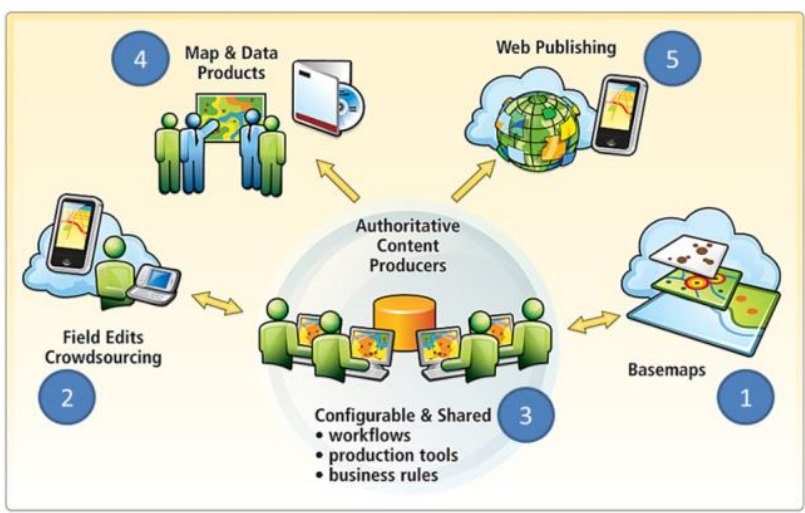

Figure 11. Workflow of GIS

Geographic Information Systems (GIS) are essential tools for geography education. It's a hardware-plus-database engine system for rapidly assembling, storing, updating, analysing, manipulating, and displaying spatially related data, such as data identifiable by their locations. As a result of GIS, people are encouraged to think spatially, or geographically. GIS is much more than a collection of digital maps. A geographic information system (GIS) is a spatial decision-making tool. Using GIS throughout the preparedness efforts is the most effective technique to make it successful during plot management. As seen in Figure 11, GIS development procedures follow the above workflow. 


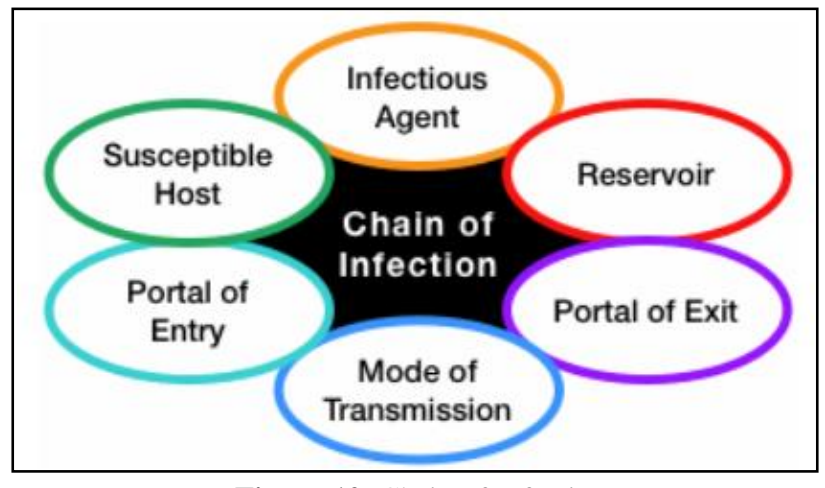

Figure 12. Chain of Infection

The spread of an illness within a community is defined as a "chain," which is made up of numerous interconnected steps that illustrate how a pathogen spreads. Infection control and contact tracing are intended to break the chain of infection and prevent the spread of a pathogen. The spread of infection can be visualised as a six-link chain, as shown in Figure 12.

The size of the smallest feature on a map that can be accurately represented without distorting its relative size is the spatial resolution of the map. High-resolution maps have more pixels per unit area of detail. A map's accuracy refers to how close a mapped value is in reality. For topographic maps, which are about conceptual maps, quantitative and qualitative data, maps must be legible, provide visual contrast between elements, have a good figure to ground organisation, have a basis for differentiating elements, have a closed form, present familiar elements in recognisable ways, and have a good contour interval.

The inputs, outputs, and steps in the process are the main components of a process map. There will be a good method as well as a decent map. Figure, scale, frame, legend, ground, title, and credits are some of the elements that make up a map.

The figure, ground, and frame are all basic map elements, as are the title, legend, scale, and source, which are all prevalent on maps. These aspects are then combined with design concepts like hierarchy and balance, as well as symbolism tools like geometry and visual variables like shape, size, colour, and value.

\section{CONCLUSION}

In conclusion, some elements and tools have been introduced in this paper that are essential to create a precise information or datasets of diseases. Big data analysis is an important element and method towards achieving precise disease mapping and predicting the risk assessments among individuals, society and public health. Big data has enabled more widespread and specific research and trials of stratifying and segmenting populations at risk for a variety of health problems. Examples of success using big data are surveyed in surveillance and signal detection, predicting future risk, targeted interventions, and understanding disease. Big data success is a required pillar for future precision public health in Malaysia.

\section{ACKNOWLEDGEMENTS}

The authors would like to thank to management of Faculty of Architecture, Planning and Surveying UiTM Shah Alam, Selangor for the sponsorship of the publication.

\section{REFERENCES}

Alene, K. A., Viney, K., Gray, D. J., McBryde, E. S., Wagnew, M., \& Clements, A. C. A. (2019). Mapping tuberculosis treatment outcomes in Ethiopia. BMC Infectious Diseases, 19(1), 1-11. https://doi.org/10.1186/s12879-019-4099-8

Biggeri, A., \& Catelan, D. (2012). Disease Mapping. In Statistical Methods in Healthcare. https://doi.org/10.1002/9781119940012.ch9

Dlamini, S. N., Beloconi, A., Mabaso, S., Vounatsou, P., Impouma, B., \& Fall, I. S. (2019). Review of remotely sensed data products for disease mapping and epidemiology. Remote Sensing Applications: Society and Environment, 14(October 2017), 108-118. https://doi.org/10.1016/j.rsase.2019.02.005

Dolley, S. (2018). Big data's role in precision public health. Frontiers in Public Health, 6(March), 1-12. https://doi.org/10.3389/fpubh.2018.00068

Fisher, R. P., \& Myers, B. A. (2011). Free and simple GIS as appropriate for health mapping in a low resource setting: A case study in eastern Indonesia. International Journal of Health Geographics, 10, 1-11. https://doi.org/10.1186/1476-072X-1015

Lawson, A., \& Lee, D. (2017). Bayesian Disease Mapping for Public Health. In Handbook of Statistics (1st ed., Vol. 36). https://doi.org/10.1016/bs.host.2017.05.001

Liu, Y., Zheng, X., Ai, G., Zhang, Y., \& Zuo, Y. (2018). Generating a high-precision true digital orthophoto map based on UAV images. ISPRS International Journal of GeoInformation, 7(9). https://doi.org/10.3390/ijgi7090333

Murad, A., \& Khashoggi, B. F. (2020). Using GIS for disease mapping and clustering in Jeddah, Saudi Arabia. ISPRS International Journal of Geo-Information, 9(5). https://doi.org/10.3390/ijgi9050328

Patterson, B., Morrow, C. D., Kohls, D., Deignan, C., Ginsburg, S., \& Wood, R. (2017). Mapping sites of high TB transmission risk: Integrating the shared air and social behaviour of TB cases and adolescents in a South African township. Science of the Total Environment, 583, 97-103. https://doi.org/10.1016/j.scitotenv.2017.01.026

Salje, H., Paul, K. K., Paul, R., Rodriguez-Barraquer, I., Rahman, Z., Alam, M. S., ... Gurley, E. (2019). Nationallyrepresentative serostudy of dengue in Bangladesh allows generalizable disease burden estimates. ELife, 8, 2013-2015. https://doi.org/10.7554/eLife.42869

Selvik, J. T., \& Abrahamsen, E. B. (2017). On the meaning of accuracy and precision in a risk analysis context. Proceedings of the Institution of Mechanical Engineers, Part O: Journal of Risk $\begin{array}{lll}\text { and } & \text { Reliability, 231(2), }\end{array}$ https://doi.org/10.1177/1748006X16686897

Tchuem Tchuenté, L. A., Stothard, J. R., Rollinson, D., \& Reinhard-Rupp, J. (2018). Precision mapping: An innovative tool and way forward to shrink the map, better target interventions, and accelerate toward the elimination of schistosomiasis. PLoS Neglected Tropical Diseases, 12(8), 2018-2021. https://doi.org/10.1371/journal.pntd.0006563 
Abdul Rasam, A. R., Mohd Shariff, N., Dony, J. F., \& Othman, F. (2019). Spatial and Statistics for Profiling Risk Factors of Diseases: A Case Study of Tuberculosis in Malaysia. IOP Conference Series: Earth and Environmental Science, 385(1). https://doi.org/10.1088/1755-1315/385/1/012037

Awang, H., Raub, N., Alias, A. N. A., Rahman, N. A. A., \& Dollah, Z. (2019). Predictors of Tuberculosis Relapse in Pasir Puteh District, Kelantan: a Case-Control Study. International Journal of Public Health \& Clinical Sciences (IJPHCS), 6(6), 133-147. Retrieved from http://search.ebscohost.com/login.aspx?direct=true $\& \mathrm{db}=\operatorname{cin} 20 \&$ $\mathrm{AN}=141202949 \&$ site=ehost-live\&authtype=ip, uid

Kaur, K. K., Said, S. M., Lim, P. Y., \& Ismail, S. N. S. (2020). Urbanization and tuberculosis in Peninsular, Malaysia (20112015). Malaysian Journal of Medicine and Health Sciences, 16(9), 63-69.

Lye Koh, H., Naim Abdul Kadir, M., M. Noordin, N., \& Yean Teh, S. (2019). Tuberculosis Elimination in Malaysia by 2035: Linkages and Implications to SDGs. International Journal of Social Science and Humanity, 9(4), 126-132. https://doi.org/10.18178/ijssh.2019.v9.1003

Mohd Salleh, S. F., Rahman, N. A. A., Rahman, N. I. A., \& Haque, M. (2018). Knowledge, attitude and practice towards tuberculosis among community of Kulim Municipal Council, Kedah, Malaysia. International Medical Journal, 25(5), 299303.

Mohidem, N. A., Hashim, Z., Osman, M., Muharam, F. M., Elias, S. M., \& Shaharudin, R. (2020). Environment as the risk factor for tuberculosis in Malaysia: A systematic review of the literature. Reviews on Environmental Health, (December). https://doi.org/10.1515/reveh-2020-0096

Mohidem, N. A., Hashim, Z., Osman, M., Shaharudin, R., Muharam, F. M., \& Makeswaran, P. (2018). Demographic, socio-economic and behavior as risk factors of tuberculosis in Malaysia: A systematic review of the literature. Reviews on Environmental Health, 33(4), 407-421. https://doi.org/10.1515/reveh-2018-0026

Rasam, A. R. A., Shariff, N. M., \& Dony, J. F. (2020). Geographical information system and geostatistical modelling approach for spatial risk assessment of tuberculosis dynamics. Test Engineering and Management, 82(February), 1193111940.

Shanmuganathan, R., \& Subramaniam, I. D. ev. (2015). Clinical manifestation and risk factors of tuberculosis infection in Malaysia: case study of a community clinic. Global Journal of Health Science, 7(4), 110-120. https://doi.org/10.5539/gjhs.v7n4p110

Swarna, N. Y. (2014). A review of tuberculosis research in malaysia. Medical Journal of Malaysia, 69(August), 88-102. Sweetland, A. C., Kritski, A., Oquendo, M. A., Sublette, M. E., Pala, A. N., Silva, L. R. B., ... Wainberg, M. L. (2017). Addressing the tuberculosis-depression syndemic to end the tuberculosis epidemic. International Journal of Tuberculosis and Lung Disease, 21(8), 852-861. https://doi.org/10.5588/ijtld.16.0584

Uden, L., Barber, E., Ford, N., \& Cooke, G. S. (2017). Risk of Tuberculosis Infection and Disease for Health Care Workers:
An Updated Meta-Analysis. Open Forum Infectious Diseases, 4(3), 1-7. https://doi.org/10.1093/ofid/ofx137

Wong, C. C., Faizul Azli, M. R., \& Loo, S. C. (2019). The Level of Risk Disclosure and Affect on Construction Public Listed Companies Performance. Malaysian Construction Research Journal, 8(3), 150-162.

Jia, P. (2019). Spatial lifecourse epidemiology. The Lancet Planetary Health, 3(2), e57-e59. https://doi.org/10.1016/S25425196(18)30245-6

Jia, Q., Guo, Y., Wang, G., \& Barnes, S. J. (2020). Big data analytics in the fight against major public health incidents (Including COVID-19): A conceptual framework. International Journal of Environmental Research and Public Health, 17(17), 1-21. https://doi.org/10.3390/ijerph17176161 